\title{
A Point-of-Care test for facing the burden of undiagnosed celiac disease in the Mediterranean area: a pragmatic design study
}

\author{
Stefano Costa ${ }^{1}$, Luca Astarita², Mongi Ben-Hariz ${ }^{3}$, Giovanni Currò ${ }^{1}$, Jernej Dolinsek ${ }^{4}$, Aydan Kansu ${ }^{5}$, \\ Giuseppe Magazzu ${ }^{\prime{ }^{*}}$, Stefania Marvaso ${ }^{1}$, Dusanka Micetic-Turku', Salvatore Pellegrino ${ }^{1}$, Giuseppe Primavera ${ }^{6}$, \\ Pasqualino Rossi ${ }^{7}$, Andrea Smarrazzo ${ }^{2}$, Francesca Tucci ${ }^{2}$, Carmela Arcidiaco ${ }^{2}$ and Luigi Greco 2,8
}

\begin{abstract}
Background: We aimed at assessing the factors that can influence results of the dissemination of an already validated, new generation commercial Point-of-Care Test (POCT) for detecting celiac disease (CD), in the Mediterranean area, when used in settings where it was designed to be administered, especially in countries with poor resources.

Methods: Pragmatic study design. Family pediatricians at their offices in Italy, nurses and pediatricians in Slovenia and Turkey at pediatricians', schools and university primary care centers looked for CD in 3,559 (1-14 yrs), 1,480 (14-23 yrs) and 771 (1-18 yrs) asymptomatic subjects, respectively. A new generation POCT detecting lgA-tissue antitransglutaminase antibodies and IgA deficiency in a finger-tip blood drop was used. Subjects who tested positive and those suspected of having CD were referred to a Celiac Centre to undergo further investigations in order to confirm CD diagnosis. POCT Positive Predictive Value (PPV) at tertiary care (with Negative Predictive Value) and in primary care settings, and POCT and $C D$ rates per thousand in primary care were estimated.

Results: At tertiary care setting, PPV of the POCT and 95\% CI were 89.5 (81.3-94.3) and 90 (56-98.5) with Negative Predictive Value 98.5 (94.2-99.6) and 98.7\% (92-99.8) in children and adults, respectively. In primary care settings of different countries where POCT was performed by a different number of personnel, PPV ranged from 16 to 33\% and the CD and POCT rates per thousand ranged from 4.77 to 1.3 and from 31.18 to 2.59 , respectively.

Conclusions: Interpretation of POCT results by different personnel may influence the performance of POC but dissemination of POCT is an urgent priority to be implemented among people of countries with limited resources, such as rural populations and school children.
\end{abstract}

Keywords: Celiac disease, Diagnosis, Mediterranean area, Point-of-care test, Rapid test

\section{Background}

Celiac Disease (CD) is a systemic immune-mediated disorder triggered by dietary gluten in genetically susceptible persons and is characterized by a broad range of clinical presentations and variable damage to the small-intestinal mucosa [1].

The active disease is characterized by gluten-dependent auto-antibodies against endomysium and, more precisely, protein type 2 ('tissue') transglutaminase, the celiac

\footnotetext{
* Correspondence: magazzug@unime.it

${ }^{1}$ Celiac Regional Center, Pediatric Gastroenterology and Cystic Fibrosis Unit, University of Messina, Via Consolare Valeria 1, 98125 Messina, Italy Full list of author information is available at the end of the article
}

autoantigen anchored to endomysial collagen by fibronectin $[2,3]$

Detection of these auto-antibodies in serum represents a valuable tool for identifying new celiac patients presenting with only mild gastro-intestinal symptoms, non-specific general complaints or extra-intestinal manifestations, or for screening asymptomatic subjects $[4,5]$. The prevalence of $\mathrm{CD}$ in various populations is around 1\% [6-8].

The burden of unrecognized CD in the Mediterranean area has been estimated in terms of morbidity costs and mortality [9]. The projected number of $\mathrm{CD}$ diagnoses in 2020 is 5 million cases ( 1 million celiac children), with a relative increase of $11 \%$ compared to 2010 . The estimated 
standardized medical costs for symptomatic celiac patients during the delay between symptom onset and diagnosis (mean - 6 years for adults, 2 years for children) will be about $€ 4$ billion ( $€ 387$ million for children) over the next 10 years. A delay in diagnosis is expected to increase morbidity, in terms of nutritional deficiencies and, especially, of gluten related autoimmune diseases and mortality: about 600,000 celiac patients will die in the next 10 years, with an excess of $44.4 \%$ versus age- and sex-matched controls. In order to face this non-communicable epidemic, it is necessary to have accurate tests available.

IgA anti tissue transglutaminase antibodies (IgA-tTG) from commercial enzyme-linked immunosorbent assays (ELISA) utilized for CD testing require a serum sample, need equipped laboratories and are too expensive for countries with poor resources, such as most of those in the Mediterranean area, where patients and families are not able to reach referral centers or centralized laboratories located far away.

Due to the necessity of drawing blood in a CD screening study, $30 \%$ of parents of children initially selected refused blood sampling [10].

There is thus the need for quick, easy-to-perform, lowcost and widely accessible celiac antibody tests which can be carried out at the Point-of-Care (POC) in countries with poor resources.

For this reason, a rapid test for detecting $\mathrm{CD}$ was developed more than 20 years ago [11].

Since this first home-made assay, which was not applied in clinical practice, several articles have recently been published on new commercial rapid tests [12-31], regarding also an assay which detects anti-deamidated gliadin peptides [31].

Among these, a POC test (POCT) has already been validated, mostly in tertiary centers $[13,15-18,20,22,23,26,27]$ and in primary care settings $[14,19,21,24,25]$. However, both the first $[14,19,21]$ and the new generation $[24,25]$ POCT have been administered by personnel, generally one person, dedicated to performing the test $[14,24]$ or by the same researchers $[21,25]$. The exception is a study performed in Hungary where 120 district nurses screened 6-year old children for $\mathrm{CD}$ with a first generation POCT and demonstrated $100 \%$ specificity, but a lower sensitivity of the test [19]. Therefore, it is important to assess if a test conceived for point-of-care utilization can maintain its accuracy in settings where it will be disseminated.

The Medicel network (www.medicel.unina.it/) is a project supported by the Italian Ministry of Health, Direction of International Affairs and comprises 16 countries with different resources and facilities (and limitations) for diagnosing $\mathrm{CD}$ [32], ranging from those that have tertiary level CD centers and family doctors to those in which, apart from lack of facilities and personnel, there are economic restraints for referring patients suspected of having celiac disease to Health Centers.

We aimed at assessing the factors that can influence results of the dissemination of an already validated new generation commercial POCT for detecting $\mathrm{CD}$, in the Mediterranean area, when it is used in the settings where it was designed to be administered.

\section{Methods}

We adopted a pragmatic design in which potential bias has been assessed. Awareness of the potential biases and its implications allows us to discuss possible solutions and overcome such bias.

Celiac centers from three countries, Italy, Slovenia and Turkey, participated in the study. Ethical institutional review boards at each collection site approved the study in the 3 centers participating in the study: in Italy, at the University Hospital, Messina; in Slovenia at the University Medical Centre Ljubljanska, Maribor; in Turkey, at the Faculty of Medicine, Ankara University, Ankara. Written informed consent for participation in the study was obtained from participants or, where participants were children, a parent or guardian.

In Table 1, demographic data of enrolled subjects and information on setting and personnel performing the test in the various countries participating in the study are shown.

The "new generation" Biocard" celiac test (AniBiotech", Vantaa, Finland), based on an immunochromatographic technique, was used. This technique detects IgA-tTG in whole blood. The procedure was performed as previously described [16]: with a drop of whole blood taken by finger prick, with bands visually detected after 5 minutes but no later than 10 minutes as recommended by the manufacturer's instructions.

Moreover, the "new generation" rapid test contains a second line (control line) with an antihuman IgA antibody. The test result is positive if both lines are seen, negative if only the control line forms. In the case of IgA deficiency, no line is visible on the test.

In Italy, the study involved 39 family pediatricians in Sicily. At their offices, all consecutive asymptomatic children were offered the POCT and those who tested positive or were found to be IgA negative on Biocard testing were referred to a Celiac Center (Group A in Table 1). Moreover, all consecutive children (Group B) and adults (Group C) referred for symptoms suggestive of $\mathrm{CD}$ by other physicians, or because they were first degree relatives of celiac patients, were enrolled at the referral Centre where they underwent both POCT, performed by a biologist or a physician, and conventional celiac serology determination.

In Slovenia, participants spontaneously underwent POCT from 6 secondary schools and 1 Medical Faculty after 
Table 1 Setting of the study, personnel performing the test and demographic data of enrolled subjects

\begin{tabular}{|c|c|c|c|}
\hline Country & Italy & Slovenia & Turkey \\
\hline \multirow[t]{3}{*}{ Setting } & $\begin{array}{l}\text { A) Primary care: Family } \\
\text { pediatrician's office }\end{array}$ & $\begin{array}{l}\text { D) Primary care - screening of secondary school } \\
\text { students - mostly in rural area of NE Slovenia }\end{array}$ & \multirow[t]{3}{*}{ Primary care: Pediatrician's office } \\
\hline & $\begin{array}{l}\text { B) Celiac centre } \\
\text { pediatric patients }\end{array}$ & $\begin{array}{l}\text { E) Students from Medical Faculty and Faculty of } \\
\text { Health Sciences University of Maribor - } \\
\text { screening }\end{array}$ & \\
\hline & $\begin{array}{l}\text { C) Celiac centre adult } \\
\text { patients }\end{array}$ & & \\
\hline \multirow{3}{*}{$\begin{array}{l}\text { Personnel } \\
\text { performing } \\
\text { POCT }\end{array}$} & $\begin{array}{l}\text { A) Family } \\
\text { pediatricians }\end{array}$ & $\begin{array}{l}\text { D) Trained nurse, student and pediatrician, } \\
\text { pediatric gastroenterologist - as supervisor }\end{array}$ & \multirow[t]{3}{*}{ Nurse and pediatrician } \\
\hline & $\begin{array}{l}\text { B) Physician and } \\
\text { biologist }\end{array}$ & $\begin{array}{l}\text { E) Trained nurse, trained students, pediatric } \\
\text { gastroenterologist - as supervisor }\end{array}$ & \\
\hline & $\begin{array}{l}\text { C) Physician and } \\
\text { biologist }\end{array}$ & & \\
\hline \multirow[t]{3}{*}{$\begin{array}{l}\text { No. subjects tested } \\
\text { (age range) }\end{array}$} & $\begin{array}{l}\text { A) } 3,559 \text { (1-14 yrs) } \\
\text { asymptomatic children }\end{array}$ & A) 1,000 (14-18y) secondary school students & \multirow[t]{3}{*}{$\begin{array}{l}771 \text { (1-18 years) asymptomatic children at school } \\
\text { (666) and at a primary care pediatrician's office (105 }\end{array}$} \\
\hline & $\begin{array}{l}\text { B) } 206 \text { (1-18 yrs) children } \\
\text { for suspected CD }\end{array}$ & B) 480 (18-23y) University students & \\
\hline & $\begin{array}{l}\text { C) } 85 \text { (>18 yrs) adults for } \\
\text { suspected CD }\end{array}$ & & \\
\hline
\end{tabular}

public invitation. POCT was performed by one pediatrician, one trained nurse and 2 trained students with a pediatric Gastroenterologist as supervisor. Subjects who tested positive or with no line were sent to the Referral Celiac Center to undergo conventional celiac serology.

In Turkey, asymptomatic children at school and at a primary care pediatrician's office underwent POCT performed by trained pediatricians and nurses. All children who tested positive or were found to be IgA negative on Biocard testing were referred to a tertiary level center to undergo celiac conventional serology.

In all the Centers, conventional IgA-tTG assays were performed with one of the kits recommended by ESPGHAN [33].

Subjects who had positive serology underwent upper gastrointestinal endoscopy with duodenal biopsies. Histology was classified according to the Marsh criteria modified by Oberhuber [34]. All patients definitively diagnosed as having celiac disease were consequently given a glutenfree diet.
Sensitivity, specificity, Positive and Negative Predictive Value (PPV and NPV, respectively) and positive and negative likelihood ratio were calculated for POCT performed in patients referred to the Celiac Center in Italy. Intestinal biopsy was performed in all subjects in whom one of the tests, including POCT, was positive at the Center, and Marsh type 2 (in children) or 3 at histology was considered the gold standard of CD diagnosis.

Positive Predictive Value of POCT and rate per thousand positive POCT and CD were calculated for subjects in whom POCT was performed by different persons in other settings. In these cases, intestinal biopsy was performed if one of the conventional celiac serology tests was positive and histology was considered the gold standard. False positive POCTs were considered subjects with normal conventional celiac serology, as, in these asymptomatic children, performing intestinal biopsy was judged unethical.

At tertiary centers, laboratory personnel were blinded to POCT results while assaying celiac conventional serology.

Table 2 Diagnostic accuracy of POCT at the Italian Celiac Centre

\begin{tabular}{llllllllll}
\hline Subjects & $\begin{array}{l}\text { No. } \\
\text { Tested }\end{array}$ & $\begin{array}{l}\text { No. positive } \\
\text { (No.CD found) }\end{array}$ & $\begin{array}{l}\text { No. negative } \\
\text { (No.CD found) }\end{array}$ & $\begin{array}{l}\text { Sensitivity } \\
\%\end{array}$ & $\begin{array}{l}\text { Specificity } \\
\%\end{array}$ & PPV \% & NPV \% & LR + & LR - \\
\hline Paediatric & 206 & 76 & 130 & 97.1 & 94.1 & 89.5 & 98.5 & 16.5 & 0.03 \\
& & $(68)$ & $(2)$ & $(93.1-100)$ & $(90.1-98.1)$ & $(81.3-94.3)$ & $(94.2-99.6)$ & $(8.4-32.39)$ & $(0.01-0.12)$ \\
Adult & \multirow{2}{*}{85} & 10 & 75 & 90.0 & 98.7 & 90.0 & 98.7 & 67.5 & 0.10 \\
& & $(9)$ & $(1)$ & $(70.4-100)$ & $(96.1-100)$ & $(56.0-98.5)$ & $(92.0-99.8)$ & $(9.5-478)$ & $(0.02-0.65)$ \\
\hline
\end{tabular}

$(95 \% \mathrm{Cl})$.

PPV: Positive Predictive Value.

NPV: Negative Predictive Value.

LR: Likelihood ratio. 
Table 3 Rate of positive Point-of-care Test and Celiac disease found according to personnel performing the test

\begin{tabular}{|c|c|c|c|c|c|c|}
\hline \multirow[b]{2}{*}{ Country } & \multirow[b]{2}{*}{ Persons (and No.) performing test } & \multirow[b]{2}{*}{ Subjects tested } & \multirow[b]{2}{*}{$\mathrm{POCT}+(\mathrm{PPV})$} & \multirow[b]{2}{*}{$\mathrm{CD}$} & \multicolumn{2}{|c|}{ Rate per thousand } \\
\hline & & & & & POCT + & CD \\
\hline ITALY & Family (39) pediatricians & 3559 & $111(16 \%)$ & 17 & 31.18 & 4.77 \\
\hline \multirow[t]{3}{*}{ SLOVENIA } & Nurse (1) & 1480 & $18(33 \%)$ & 7 & 12.16 & 4.72 \\
\hline & Student (2) & & & & & \\
\hline & Pediatrician (1) & & & & & \\
\hline TURKEY & Pediatrician (2) Nurse (1) & 771 & $2^{*}$ (N.A.) & 1 & 2.59 & 1.30 \\
\hline
\end{tabular}

*1 patient was not referred to Center to undergo conventional serology and histology and thus PPV was Not Available (NA).

CD: Celiac Disease.

POCT: Point-of-Care Test.

\section{Results}

In Table 2, the performance of POCT at the Italian Celiac Center is shown.

In Table 3, POC PPV and rates per thousand for POCT and $C D$ are shown.

The lowest PPV was found in Italy and Slovenia but in these countries POCT yielded a high rate of positive cases and of CD.

All false positive cases of POCT (84\%) performed by pediatricians in primary care in Italy were negative at the POCT performed at the Center by a well experienced biologist or physician. In Slovenia, there were 67\% false positive cases while it was not possible to estimate the number in Turkey as, out of 2 children with positive POCT, one refused referral to the Celiac Center.

Diagrams of results obtained in Italy, Slovenia and Turkey are shown in Figures 1, 2 and 3, respectively.

In Italy (Figure 1), out of 45 cases who had no line visible on the test, 37 had normal IgA at the Center. In one of these, IgA-tTG was high and histology confirmed CD. In another case with confirmed IgA deficiency, IgG-tTG was high and histology confirmed CD. Out of 20 children with

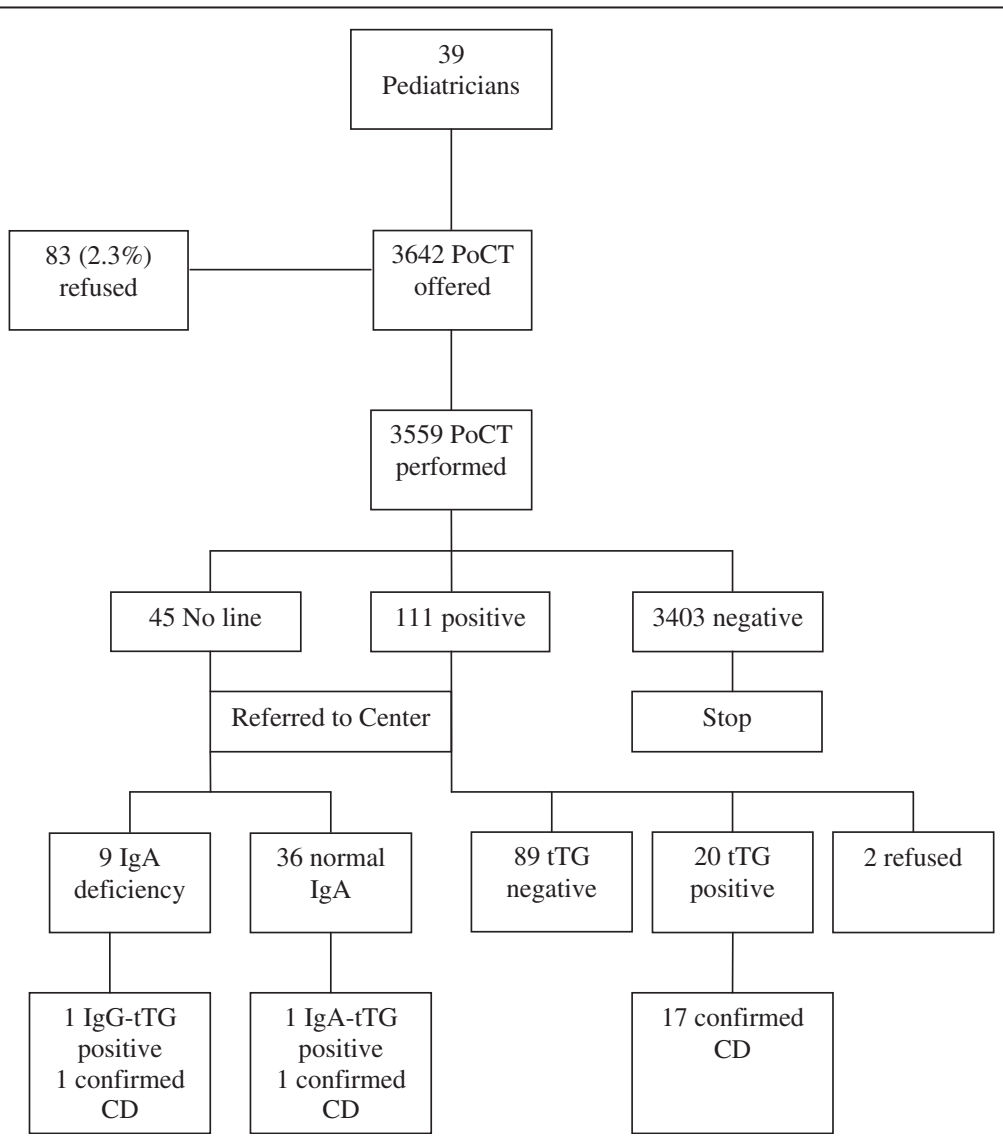

Figure 1 Results in primary care in Italy. Abbreviations: PoCT= Point-of-Care Test; tTG = anti-tissue transglutaminase antibodies. 
positive tTG confirmed at the Center, 3 had low titers of tTG ( $<4 \mathrm{X}$ upper limit of normal) and absent antiendomysial antibodies. Following requests by the families, the children have not yet undergone duodenal biopsy and are in follow up with a gluten containing diet. The lowest ELISA value among the 17 children with POCT positive in whom $\mathrm{CD}$ diagnosis was confirmed was about four fold the cutoff.

The refusal rate of parents to allow their children to undergo POCT in the pediatrician's office was $2.3 \%$.

In Slovenia (Figure 2) the refusal rate was not estimable due to the spontaneous participation of subjects after public invitation.

In Turkey (Figure 3) the refusal rate was 1.7\%. One family refused duodenal biopsy in one out of the 2 children who resulted tTG positive and, therefore, it was not possible to estimate $\mathrm{CD}$ rate per thousand (Table 3).

\section{Discussion}

Our pragmatic study was aimed at getting information to then disseminate a well validated, cheap and rapid test for $C D$ that does not require an equipped laboratory, above all in some Mediterranean countries where most of the patients do not have enough resources to reach a referral centre.

The ideal test should be cheap and feasible, with very high sensitivity and specificity.
Considering that the POCT used in our study has previously been validated, and that its high diagnostic accuracy has been confirmed in the present study at the tertiary level center in Italy, variations in PPV of the new generation POCT do not depend on the test but rather, apart from the prevalence of higher $C D$ in tertiary care centers than in community settings, on the operator and interpretation of test. It is of interest that in our study, the lowest PPV was obtained in settings where the POCT was performed by more than one operator, such as primary care pediatricians in their office or personnel who are not completely dedicated to performing diagnostic procedures. In Slovenia, where all the POCTs were supervised by a skilled pediatric gastroenterologist with long experience with these tests, a lower level of false positive was obtained in comparison with that observed among primary care pediatricians. In a screening study performed in Tunisia, using the same new generation POCT [25], the interpretation of faint test lines explained different PPVs obtained. Moreover, in a previous study performed in Hungary by 120 non-trained district nurses [19], in which each one performed a median of 18 first generation POC tests, specificity was $100 \%$ but sensitivity of the test was low. These results may be due, as the authors suggested, to the lower sensitivity obtained on site by the nurses interpreting faint test lines as negative results. In our study, differences between positive tests and faint test

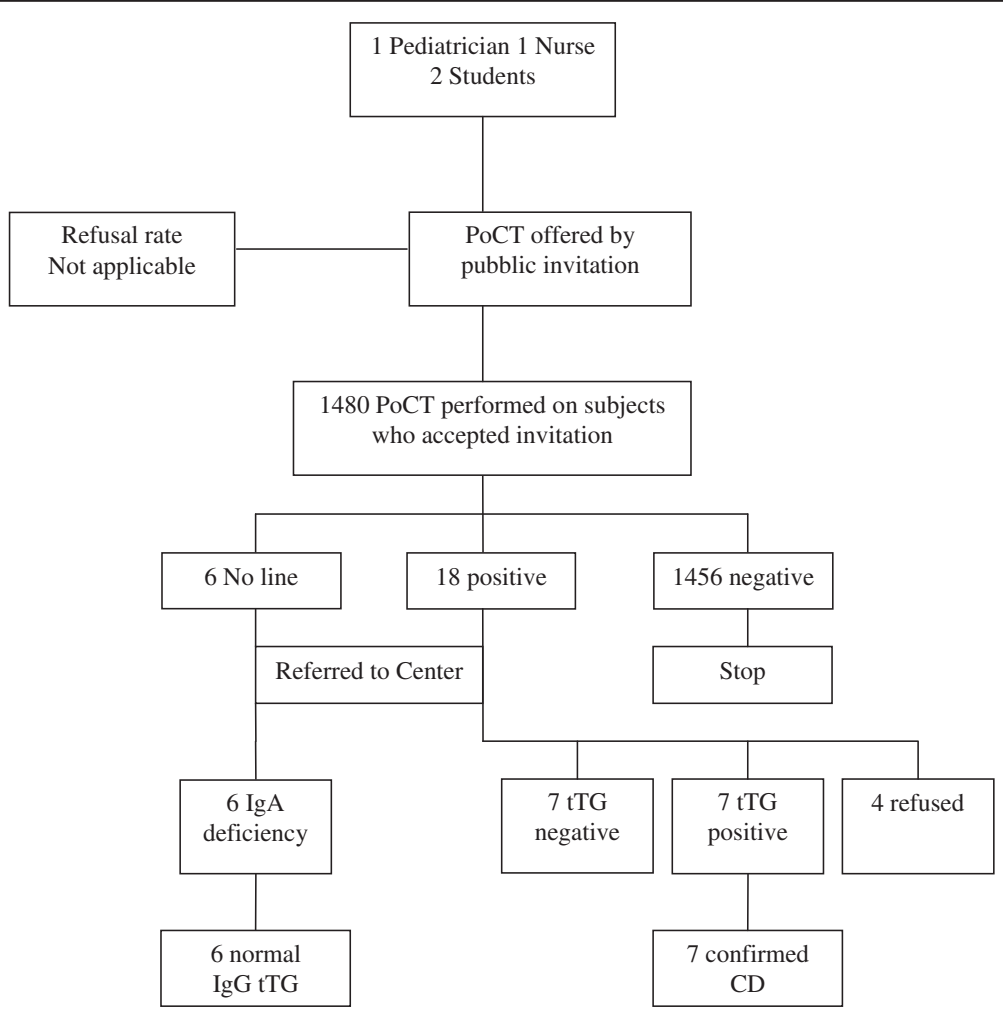

Figure 2 Results in primary care in Slovenia. Abbreviations: PoCT= Point-of-Care Test; tTG = anti-tissue transglutaminase antibodies. 


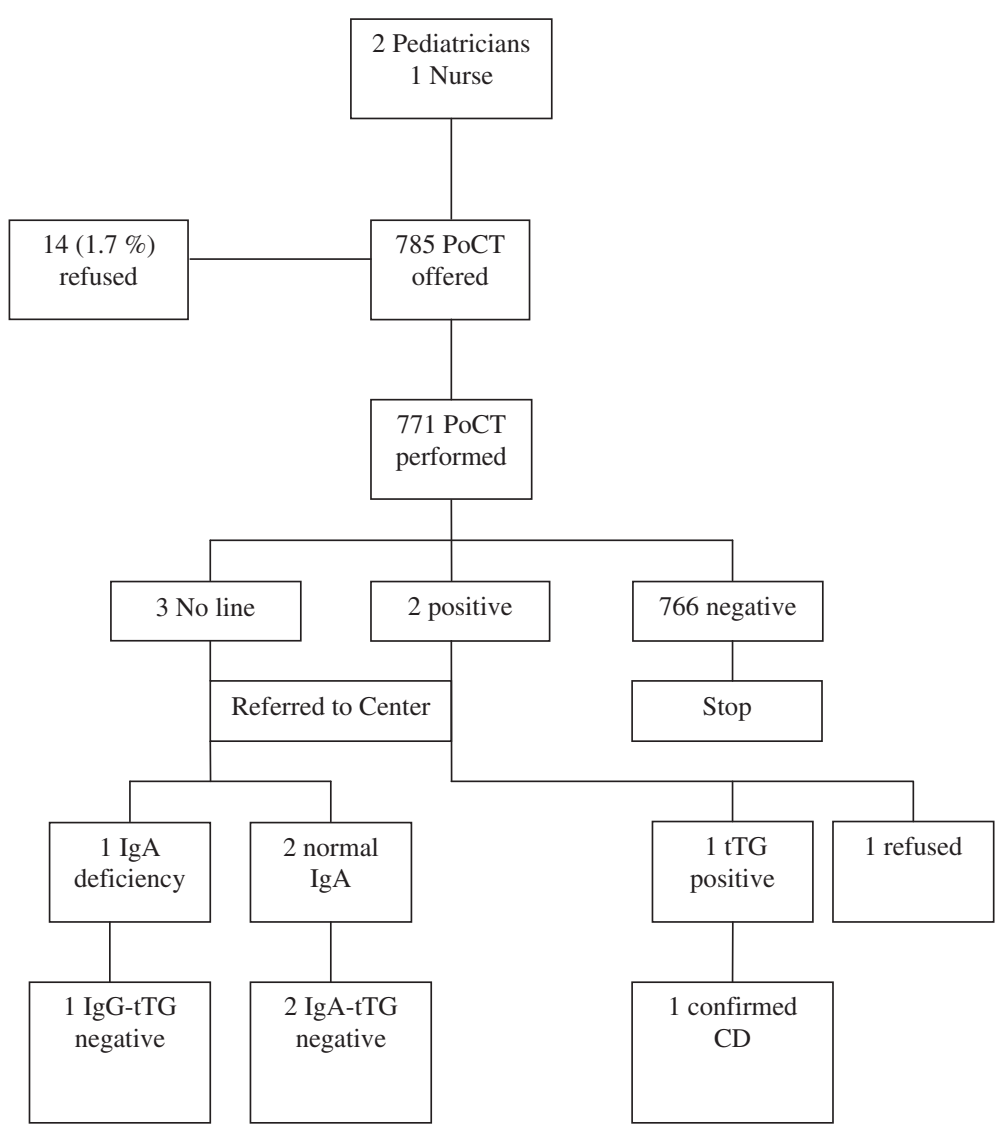

Figure 3 Results in primary care in Turkey. Abbreviations: PoCT= Point-of-Care Test; tTG = anti-tissue transglutaminase antibodies.

lines were not recorded. Therefore, we can only speculate that personnel in primary care also referred subjects to the Center with faint test lines who afterwards tested negative at conventional serology, as shown in a previous study [25]. On the other hand, it was reported that doubtful results with faint lines of positivity have actually been observed at the end of the reading time recommended by the manufacturer (9-10 minutes). Further investigation by serology revealed that all of these "doubtful" results were false positive [25]. Unfortunately, we did not record the test reading exact time and participants were asked to read the test within 10 minutes as recommended by the manufacturer.

In countries with poor resources, it would be advisable for this POCT to be performed by a minimum number of trained people, in order to minimize costs induced by false positive cases.

Two previously published studies which were performed in two centers (Greece and Tunisia) from countries participating in the Medicel network, using the same POCT, obtained the highest PPV $(100 \%)[24,25]$.

In Greece [24], properly trained nonmedical staff performed the POCT on toddlers attending nursing school.
In Tunisia [25], screening for CD by POCT was performed by a team of 3 doctors and a nurse previously trained in reading the test. Among the children who tested negative with POCT, a small sample consisting of the first 54 were called in for conventional testing in order to assess NPV of the test. NPV, although estimated in a small sample, was $100 \%$.

In the present study, NPV of POCT was assessed in a tertiary level Centre in a population with high and moderate prevalence of $C D$, such as that represented by patients referred with the suspicion of $\mathrm{CD}$ and first degree relatives, respectively. POCT at the tertiary centre, and in a population with the above cited prevalence of $C D$, had a very high NPV but this must be assessed in settings other than a Celiac centre and in populations with low prevalence of CD. NPV was previously reported lower in a study performed in Libyan children who participated in a screening study but the results were based on a first generation POCT [21]. However, while waiting for further studies aimed at assessing NPV by assaying conventional $\mathrm{CD}$ serology in patients with negative POCT, we believe that it is cost-effective to start huge case finding and, above all, screening strategies $[35,36]$ based on POCT 
in order to face the epidemic of $\mathrm{CD}$ and decrease morbidity, mortality and costs in the Mediterranean area [9,32]. These costs, even in the worst possible scenario, allow us to save money due to the excessive costs of patients with undiagnosed $\mathrm{CD}$, keeping in mind that the so-called active case-finding may fail to identify the majority of them $[35,36]$.

\section{Conclusions}

Our study suggests that factors that can influence the results of a POCT dissemination in the Mediterranean area, apart from the prevalence of $\mathrm{CD}$ in different settings where it is applied, include interpretation of results by appropriately trained personnel performing the test. More studies are needed to decide the correct time limit for test and interpretation of faint lines.

We believe that the populations amongst which the dissemination of POCT would be of the greatest benefit and where it is most "urgent" to implement are in countries with limited resources, above all rural populations where most of the people are not able to reach the referral centres.

\section{Abbreviations}

CD: Celiac disease; IgA-tTG: IgA-tissue antitransglutaminase antibodies; POCT: Point-of-Care Test.

\section{Competing interests}

The authors declare that they have no competing interests.

\section{Authors' contributions}

SC, MB-H, AK, DM-T, GM and LG planned the study, analyzed data and drafted the article. $L A, G C, J D, S M, G P, E R, P R, A S, F T$, MA gave substantial contributions to conception and design, acquisition and interpretation of data, revising the article critically for important intellectual content. All authors read and approved the final manuscript.

\section{Acknowledgments \\ GP participated in the study on behalf of the following pediatricians from Associazione Culturale Pediatri Sicilia who approved the study design and collected data: Vittoria Agnello, Anna Aloisio, Biagio Amoroso, Anna Armenio, Alba Barresi, Letizia Belvedere, Francesca Bontempo, Eleonora Cacioppo, Rosaria Cambria, Cristoforo Cocchiara, Sergio Conti Nibali, Isodiana Crupi, Cristina D'Andrea, Francesca Di Leonardo, Mirella Di Matteo, Antonino Gennaro, Francesca Grassa, Nicola Lamacchia, Antonina Lo Cascio, Gianvera Lo lacono, Francesca Lupo, Rita Marchese Ragona, Vincenzo Montalbano, Caterina Morana, Giulia Papa D’Amico, Sandro Paparone, Domenica Pennino, Michele Pipia, Giuseppe Portera, Benedetto Rinaudo, Elisa Sanfilippo, Vincenzo Sannasardo, Maria Francesca Siracusano, Angelo Spataro, Sergio Speciale, Monica Tulumello, Maria Testoni, Daniela Zangara. \\ MEDICEL network components participated in the study on behalf of others who approved the design of the study: \\ Abdelhak Abkari, Morocco, Mona Ambu-Zekry, Egypt, Thomas M Attard, Malta, Karim Bouziane-N., Algeria, Jose Ranon Bilbao, Spain, Veselinka Djurisic, Montenegro, Jean-Pierre Hugot, France, Sanja Kolacek, Croatia, Zrinjka Misak, Croatia, Eleftheria Roma, Greece, Selma Terzic, Bosnia, Virtut Velmishi, Albania. Engin Yurdakul and Ayşe Fahriye Genç performed the POCT at schools and also at their office in Turkey. \\ We thank Trays Macdonnell for revising the English of the article.}

\section{Disclosure of funding}

Italian Ministry of Health, Directorate General for European and International Relations; Euromed action. Project: "Food-induced diseases-Celiac Disease (Medicel)-Phase II" (CUP n E61J11000450001).

\section{Author details}

'Celiac Regional Center, Pediatric Gastroenterology and Cystic Fibrosis Unit, University of Messina, Via Consolare Valeria 1, 98125 Messina, Italy. ${ }^{2}$ European Laboratory for Food Induced Diseases, University of Naples Federico II, Naples, Italy. ${ }^{3}$ Pediatric Unit, Mongi SLIM's Hospital of Tunis, Marsa, Tunisia. ${ }^{4}$ University Medical Centre Pediatric Department, Ljubljanska, Maribor, Slovenia. ${ }^{5}$ Faculty of Medicine, Department of Pediatric Gastroenterology, Ankara University, Ankara, Turkey. ${ }^{6}$ National Health System, Azienda Sanitaria Locale 6, Associazione Culturale Pediatri, Palermo, Italy. ${ }^{7}$ Directorate General for European and International Relations, Ministry of Health, Rome, Italy. ${ }^{8}$ Department of Translational Medical Science, Section of Pediatrics, University of Naples Federico II, Naples, Italy.

Received: 14 September 2014 Accepted: 11 December 2014 Published online: 18 December 2014

\section{References}

1. Green PHR, Cellier C: Celiac disease. N Engl J Med 2007, 357:1731-1743.

2. Dieterich W, Ehnis T, Bauer M, Donner P, Volta U, Riecken EO, Schuppan D: Identification of tissue transglutaminase as the autoantigen of celiac disease. Nat Med 1997, 3:797-801.

3. Korponay-Szabo' IR, Laurila K, Szondy Z, Halttunen T, Szalai Z, Dahlbom I Rantala I, Kovács JB, Fésüs L, Mäki M: Missing endomysial and reticulin binding of coeliac antibodies in transglutaminase 2 knockout tissues. Gut 2003, 52:199-204.

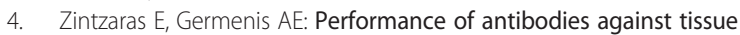
transglutaminase for the diagnosis of celiac disease: meta-analysis. Clin Vaccine Immunol 2006, 13:187-192.

5. Giersiepen K, Lelgemann M, Stuhldreher N, Ronfani L, Husby S, Koletzko S, Korponay-Szabó IR: ESPGHAN Working Group on Coeliac Disease Diagnosis. Accuracy of diagnostic antibody tests for coeliac disease in children: summary of an evidence report. JPGN 2012, 54:229-241.

6. Mäki M, Mustalahti K, Kokkonen J, Kulmala P, Haapalahti M, Karttunen T, \|lonen J, Laurila K, Dahlbom I, Hansson T, Höpfl P, Knip M: Prevalence of celiac disease among children in Finland. N Eng/ J Med 2003, 348:2517-2524.

7. Tommasini A, Not T, Kiren V, Baldas V, Santon D, Trevisiol C, Berti I, Neri E, Gerarduzzi T, Bruno I, Lenhardt A, Zamuner E, Spanò A, Crovella S, Martellossi S, Torre G, Sblattero D, Marzari R, Bradbury A, Tamburlini G, Ventura A: Mass screening for coeliac disease using antihuman transglutaminase antibody assay. Arch Dis Child 2004, 89:512-515.

8. Rubio-Tapia A, Ludvigsson JF, Brantner TL, Murray JA, Everhart JE: The prevalence of celiac disease in the United States. Am J Gastroenterol 2012, 107:1538-1544.

9. Greco L, Timpone L, Abkari A, Abu-Zekry M, Attard T, Bouguerrà F, Cullufi P, Kansu A, Micetic-Turk D, Mišak Z, Roma E, Shamir R, Terzic S: Burden of celiac disease in the Mediterranean area. World J Gastroenterol 2011, 17:4971-4978.

10. Ben Hariz M, Kallel-Sellami M, Kallel L, Lahmer A, Halioui S, Bouraoui S, Laater A, Sliti A, Mahjoub A, Zouari B, Makni S, Maherzi A: Prevalence of celiac disease in Tunisia: mass-screening study in school children. Eur $J$ Gastroenterol Hepatol 2007, 19:687-694.

11. Not T, Ventura A, Peticarari S, Basile S, Torre G, Dragovic D: A new, rapid noninvasive screening test for celiac disease. J Pediatr 1993, 123:425-427.

12. Baldas V, Tommasini A, Trevisiol C, Berti I, Fasano A, Sblattero D, Bradbury A, Marzari R, Barillari G, Ventura A, Not T: Development of a novel rapid noninvasive screening test for coeliac disease. Gut 2000, 47:628-631.

13. Nemec G, Ventura A, Martelossi S, Di Leo G, Baldas V, Tommasini A, Ferrara F, Taddio A, Città A, Sblattero D, Marzari R, Not T: Looking for celiac disease: diagnostic accuracy of Two rapid commercial assays. Am J Gastroenterol 2006, 101:1597-1600.

14. Crovella S, Brandao L, Guimaraes R, Filho JL, Arraes LC, Ventura A, Not T: Speeding up coeliac disease diagnosis in the developing countries. Dig Liv Dis 2007, 39:900-902.

15. Korponay-Szabo IR, Raivio T, Laurila K, Opre J, Király R, Kovács JB, Kaukinen K, Fésüs L, Mäki M: Coeliac disease case finding and diet monitoring by point-of-care testing. Aliment Pharmacol Ther 2005, 22:729-737.

16. Raivio T, Kaukinen K, Nemes E, Laurila K, Collin P, Kovács JB, Mäki M, Korponay-Szabó IR: Self transglutaminase-based rapid coeliac disease antibody detection by a lateral flow method. Aliment Pharmacol Ther 2006, 24:147-154. 
17. Raivio T, Korponay-Szabo' IR, Collin P, Laurila K, Huhtala H, Kaartinen T, Partanen J, Mäki M, Kaukinen K: Performance of a new rapid whole blood coeliac test in adult patients with low prevalence of endomysial antibodies. Dig Liv Dis 2007, 39:1057-1063.

18. Raivio T, Korponay-Szabò IR, Paajanen T, Ashorn M, Itanen S, Collin P, Laurila K, Nemes E, Kovács JB, Carrard G, Saramäki M, Mäki M, Kaukinen K: Comparison of a novel whole blood transglutaminase-based ELISA with a whole blood rapid antibody test and established conventional serological celiac disease assays. JPGN 2008, 47:562-567.

19. Korponay-Szabò IR, Szabados K, Pusztai J, Uhrin K, Ludmány E, Nemes E, Kaukinen K, Kapitány A, Koskinen L, Sipka S, Imre A, Mäki M: Population screening for coeliac disease in primary care by district nurses using a rapid antibody test: diagnostic accuracy and feasibility study. BMJ 2007 335:1244-1247.

20. Kotze LM, Rodrigues AP, Kotze LR, Nisihara RM: A Brazilian experience of the self transglutaminase-based test for celiac disease case finding and diet monitoring. World J Gastroenterol 2009, 15:4423-4422.

21. Alarida K, Harown J, Ahmaida A, Marinelli L, Venturini C, Kodermaz G, Tozzoli R, Mandolesi A, Bearzi I, Catassi C: Coeliac disease in Libyan children: A screening study based on the rapid determination of antitransglutaminase antibodies. Dig Liv Dis 2011, 43:688-691.

22. Laadhar L, Kallel-Sellami M, Zitouni M, Mehrezi A, Makni S, Ben Hariz M: Is the rapid whole blood test useful for diagnonis and monitoring coeliac disease in children? Tunis Med 2011, 89:16-17.

23. Oliveira A, Trindade E, Tavares M, Lima R, Terra M, Dias JA: Celiac Disease in first degree relatives of celiac children. Arq Gastroenterol 2012, 49:204-207.

24. Karagiozoglou-Lampoudi T, Zellos A, Vlahavas G, Kafritsa Y, Roma E, Papadopoulou A, Fotoulaki M, Karyda S, Xinias I, Savvidou A: Screening for coeliac disease in preschool Greek children: the feasibility study of a community-based project. Acta Paediatr 2013, 102:749-754.

25. Ben Hariz M, Laadhar L, Kallel-Sellami M, Siala N, Bouraoui S, Bouziri S, Borg A, Karouia F, Maherzi A, Makni S: Celiac disease in Tunisian children: a second screening study using a "new generation" rapid test. Immunol Invest 2013, 42:356-368.

26. Popp A, Jinga M, Jurcut C, Balaban V, Bardas C, Laurila K, Vasilescu F, Ene A, Anca I, Mäki M: Fingertip rapid point-of-care test in adult case-finding in coeliac disease. BMC Gastroenterol 2013, 3:115.

27. Singh P, Wadhwa N, Chaturvedi MK, Bhatia V, Saini S, Tandon N, Makharia GK, Maki M, Not T, Phillips A, Bhatnagar S: Validation of point-of-care testing for coeliac disease in children in a tertiary hospital in north India. Arch Dis Child 2014, 0:1-5.

28. Blesa-Baviera LC, Donat Aliaga E, Ortigosa L, Litwin N, Peña-Quintana L, Méndez V, González MV, López-Manzanares JM, Méndez E, Koninckx CR: Celiac disease screening by immunochromatographic visual assays: results of a multicenter study. JPGN 2007, 45:546-550.

29. Demirceken FG, Kansu A, Kuloglu Z, Girgin N, Güriz H, Ensari A: A Human tissue transglutaminase antibody screening by immunochromatographic line immunoassay for early diagnosis of celiac disease in Turkish children. Turk J Gastroentero/ 2008, 19:14-21.

30. George DA, Hui LL, Rattehalli D, Lovatt T, Perry I, Green M, Robinson K, Brookes MJ, Walters JRF: The role of near-patient coeliac serology testing in the follow-up of patients with coeliac disease. Gut 2011 60:A17.

31. Benkebil F, Combescure C, Anghel SI, Besson Duvanel C, Schäppi MG: Diagnostic accuracy of a new point-of-care screening assay for celiac disease. World J Gastroenterol 2013, 19:5111-5117.

32. Tucci F, Astarita L, Abkari A, Abu-Zekry M, Attard T, Ben Hariz M, Bilbao JR, Boudraa G, Boukthir S, Costa S, Djurisic V, Hugot JP, Irastorza I, Kansu A, Kolaček S, Magazzù G, Mičetić-Turk D, Misak Z, Roma E, Rossi P, Terzic S, Velmishi V, Arcidiaco C, Auricchio R, Greco L: Celiac disease in the Mediterranean area. BMC Gastroenterol 2014, 14:24.

33. Husby S, Koletzko S, Korponay-Szabo IR, Mearin ML, Phillips A, Shamir R, Troncone R, Giersiepen K, Branski D, Catassi C, Lelgeman M, Mäki M, Ribes-Koninckx C, Ventura A, Zimmer KP, ESPGHAN Working Group on Coeliac Disease Diagnosis; ESPGHAN Gastroenterology Committee; European Society for Pediatric Gastroenterology, Hepatology, and Nutrition: European society for pediatric gastroenterology, hepatology, and nutrition guidelines for the diagnosis of coeliac disease. JPGN 2012, 54:136-160.

34. Oberhuber G, Granditsch G, Vogelsang H: The histopathology of coeliac disease: time for a standardized report scheme for pathologists. Eur J Gastroenterol Hepatol 1999, 11:1185-1194.

35. Rosén A, Sandström O, Carlsson A, Högberg L, Olén O, Stenlund H, Ivarsson A: Usefulness of symptoms to screen for celiac disease. Pediatrics 2014, 133:211-218.

36. Baker SS: Rethinking strategies to screen for celiac disease. Pediatrics 2014, 133:331-332

\section{Submit your next manuscript to BioMed Central and take full advantage of:}

- Convenient online submission

- Thorough peer review

- No space constraints or color figure charges

- Immediate publication on acceptance

- Inclusion in PubMed, CAS, Scopus and Google Scholar

- Research which is freely available for redistribution

Submit your manuscript at www.biomedcentral.com/submit
C) Biomed Central 